\title{
Hormonal Phenotype and HLA-Genotype in Families of Patients with Congenital Adrenal Hyperplasia (21-Hydroxylase Deficiency)
}

\author{
FRANZISKA LORENZEN, SONGJA PANG, MARIA I. NEW, BO DUPONT, MARILYN POLLACK, \\ DIANE M. CHOW, AND LENORE S. LEVINE \\ The Division of Pediatric Endocrinology, Department of Pediatrics, The New York Hospital-Cornell Medical Center, \\ New York, New York and The Tissue Typing Laboratory, Sloan-Kettering Institute for Cancer Research (B. D.,
} M. P.), New York, New York, USA

\section{Summary}

The response of 17-hydroxyprogesterone (17-OHP) and cortisol (F) to a 6-hr ACTH stimulation in families of patients with congenital adrenal hyperplasia due to 21 -hydroxylase deficiency was studied. These studies demonstrated that siblings who should be heterozygous carriers of the 21-hydroxylase deficiency gene based on HLA genotyping are hormonally different from the general population.

In pre- and early pubertal children predicted to be heterozygous carriers of the gene based on HLA genotyping, the 17-OHP level $(13.1 \pm 4.5 \mathrm{ng} / \mathrm{ml})$, the rate of increase of $17-\mathrm{OHP}(0.03 \pm 0.01)$, and the ratio of $17-\mathrm{OHP} / \mathrm{F}$ at $6 \mathrm{hr}(0.27 \pm 0.07)$ were significantly higher $(P<0.001)$ than in the control population, $(3.9 \pm 1.9,0.009$ \pm 0.005 , and $0.08 \pm 0.04 \mathrm{ng} / \mathrm{ml}$, respectively). In late and postpubertal males, these hormonal parameters in the heterozygotes (17 $\pm 9.7,0.04 \pm 0.026,0.42 \pm 0.33 \mathrm{ng} / \mathrm{ml}$, respectively) were significantly higher $(P<0.001)$ than in the general population $(5.3 \pm$ $1.6,0.009 \pm 0.004$, and $0.1 \pm 0.03 \mathrm{ng} / \mathrm{ml}$, respectively).

In postmenarchal females, the mean hormone responses in the heterozygotes $(12.1 \pm 9.7,0.03 \pm 0.02$, and $0.27 \pm 0.24 \mathrm{ng} / \mathrm{ml}$, respectively) were significantly higher $(P<0.005,<0.01,<0.005$, respectively) than in the general population $(5.2 \pm 2.5,0.01 \pm$ 0.007 , and $0.1 \pm 0.04 \mathrm{ng} / \mathrm{ml}$, respectively). However, the overlapping values did not permit a clear differentiation of the hormonal responses in these two groups.

Another (ACTH) stimulation in one family demonstrated that a father of a patient probably is a previously unrecognized homozygous affected patient and, thus, revision of the congenital adrenal hyperplasia (CAH) genotype for this family was required.

\section{Speculation}

In families of patients with $\mathrm{CAH}$ due to 21-hydroxylase deficiency, siblings predicted to be heterozygous carriers of the gene for 21 hydroxylase deficiency based on HLA genotyping, will express a mild enzyme deficiency by hormonal testing.

CAH due to 21-hydroxylase deficiency (21-OH-def.) is an inborn error of metabolism transmitted by an autosomal recessive gene (3). Previous studies have demonstrated hormonal evidence of a mild $21-\mathrm{OH}$-def. in parents of children with $\mathrm{CAH}$ who are obligate heterozygotes $(2-4,7-10,12,13,17,18)$. However, similar studies in siblings (sibs) of patients with CAH have been difficult to interpret because of the inability to ascertain which sib was a heterozygous carrier of the gene and which sib was genetically unaffected $(2,8,9,13,17,18)$.

Recently, it has been shown that there is close genetic linkage between the HLA complex and CAH $(5,14,16,20)$. These reports suggested that HLA-genotyping may be used for the detection of heterozygosity of sibs of patients with $\mathrm{CAH}$.

The present study was undertaken to examine whether sibs who should be heterozygous carriers of the 21-OH-def. gene based on HLA-genotyping also express hormonal differences during ACTH stimulation from the general population and from the sibs who are homozygous normal according to HLA typing.

\section{MATERIALS AND METHODS}

\section{SUBJECTS}

Families of $\mathrm{CAH}$ (21 OH-Def.) HLA-genotyping and hormonal response to ACTH stimulation were determined in nine families with one or more children with CAH. A total of 38 clinically normal family members were studied. There were eight mothers, eight postmenarchal and three pre-menarchal sisters. There were six fathers, nine postpubertal and four prepubertal brothers.

By HLA-genotyping, all sisters were heterozygous whereas two of the nine brothers were homozygous unaffected. The remainder were heterozygotes. The hormonal responses of these family members are illustrated in Figures 1-3. In addition, one father and one postpubertal brother who were undiagnosed CAH patients and two known prepubertal untreated male patients with CAH were studied. The data of these patients appear in Table 1.

HLA-Typing and Assignment of CAH Genotyping. HLA-typing was performed on peripheral blood lymphocytes usirg the standard two stage NIH microcytotoxicity test. The assignment of heterozygosity for the gene for $\mathrm{CAH}$ was based on the presence of one HLA haplotype in common with the affected sib. The parents were assumed to be obligate heterozygotes for $\mathrm{CAH}$. Unaffected homozygous sibs shared no haplotypes with the affected CAH sib. Based on these assumptions, HLA genotyping revealed two unaffected homozygous brothers, one unaffected homozygous sister, 22 heterozygous sisters and brothers, and one previously undiagnosed affected brother.

General Population. Eight postpubertal males (two hospitalized normals, four normal volunteers, and two postpubertal male sibs who were homozygous unaffected for CAH according to the HLA genotype) served as the control postpubertal male general population. Four hospitalized postmenarchal females and nine postmenarchal female volunteers represented the post-menarchal female control population. The hospitalized normals underwent ACTH stimulation tests as part of an endocrine evaluation and were proven to have normal adrenal function.

All subjects were studied in the Pediatric Clinical Research Center at The New York Hospital-Cornell Medical Center after informed consent from either the study subjects or their parents was obtained.

Hormonal Evaluation and Data Analysis. Serum 17-OHP and F 


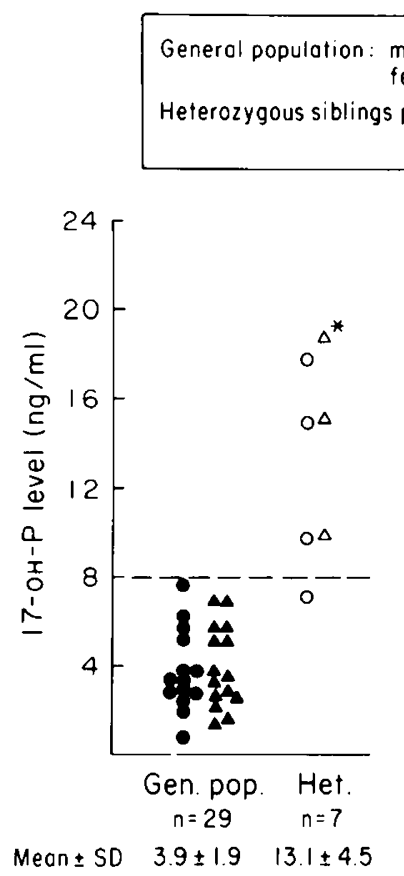

$$
\text { male }
$$

proven by HLA: male 0

femole $\Delta$
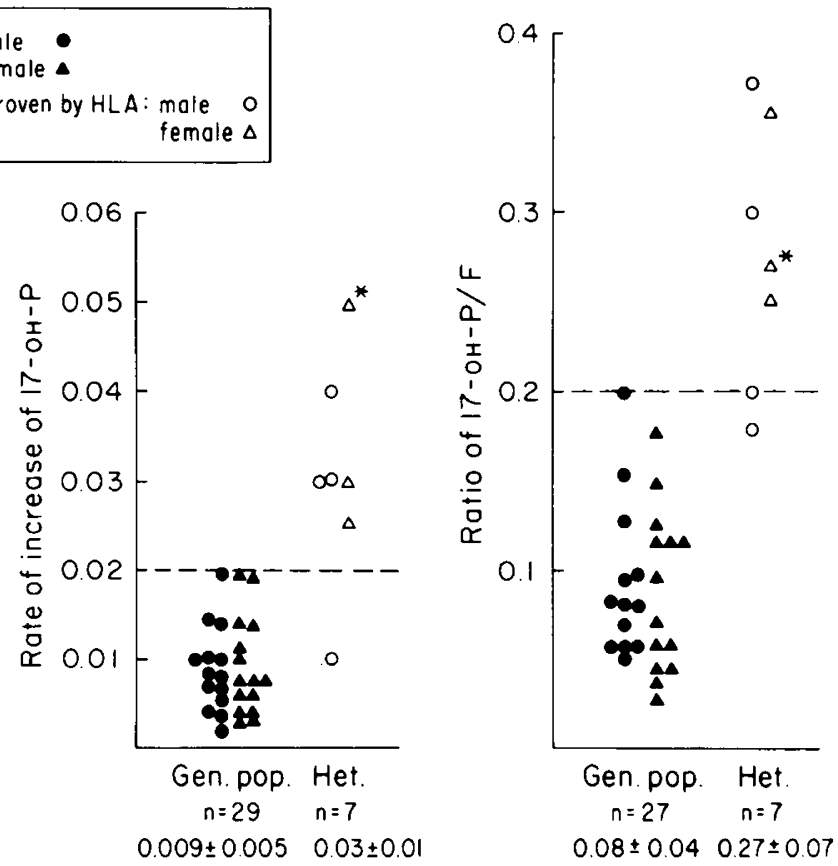

Fig. I. Hormonal response to ACTH stimulation in prepubertal and early pubertal children (Tanner I-III), gen. pop.: general population; Het: assumed to be heterozygous for CAH according to HLA genotyping; - - - : upper range in general population; $\triangle^{*}$ : offspring of a probably affected homozygous father and heterozygous mother for $\mathrm{CAH}$.

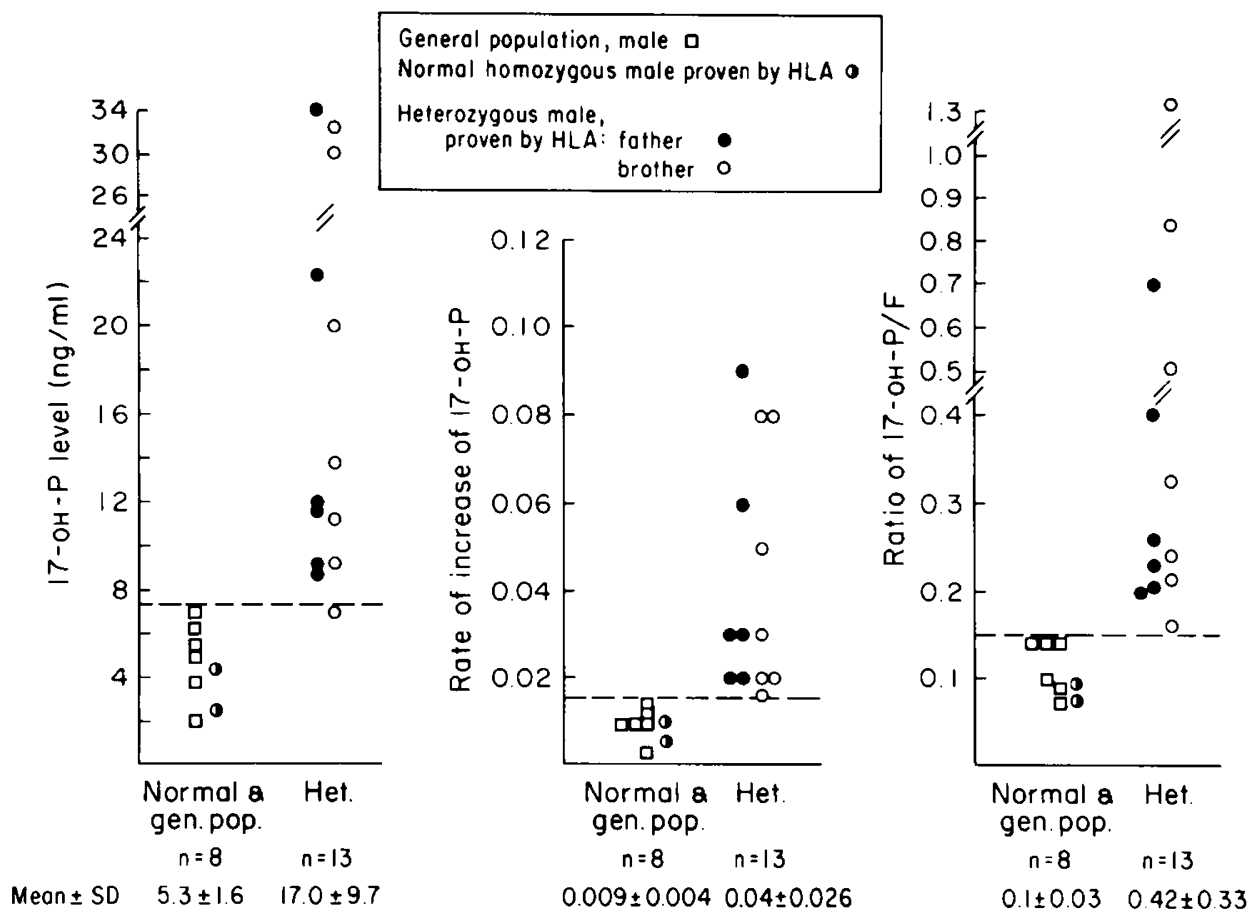

Fig. 2. Hormonal response to ACTH stimulation in late and postpubertal males (Tanner stage IV-V), Normal: normal homozygous brothers proven by HLA; gen. pop.: general population; Het: assumed to be heterozygous for CAH according to HLA genotyping; - - -: upper range in general population.

were measured before and after ACTH (40 units of Acthar) was administered iv for $6 \mathrm{hr}$. Serum 17-OHP was determined by radioimmunoassay as previously described (15) and serum $F$ was measured by using a modified radioimmunoassay after celite chromatography (1). The inter- and intra-assay variability were less than $15 \%$ for both radioimmunoassay of 17-OHP and $\mathrm{F}$.

The baseline level was calculated as the mean of the -15- and 0 -min concentrations. The rate of 17-OHP was calculated as the difference between the baseline values and that after ACTH stimulation divided by the time in min.
Wilcoxon nonparametric rank test was used for statistical analysis.

\section{RESULTS}

\section{CORTISOL VALUES}

There was no significant difference in baseline or ACTH stimulated $F$ levels between the heterozygotes and the general population in all Tanner stages. 

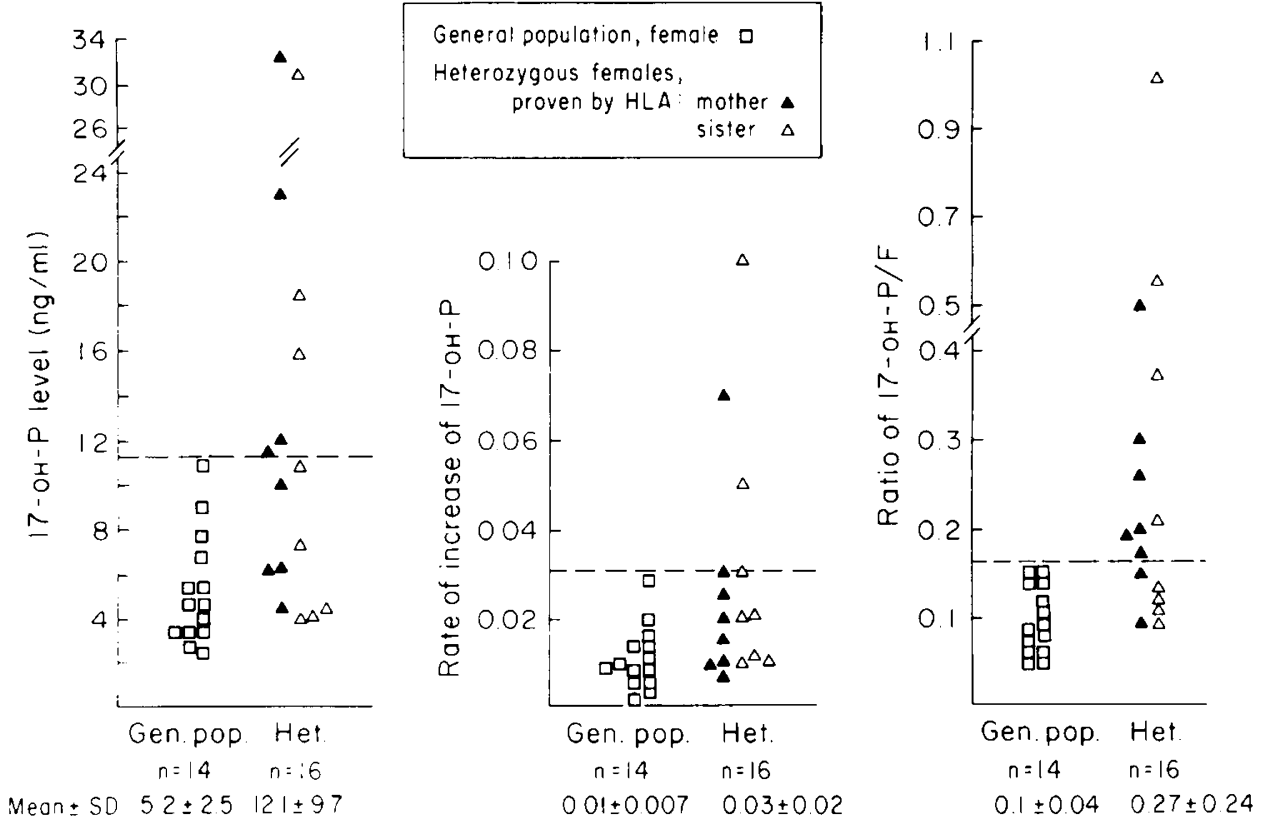

Fig. 3. Hormonal response to ACTH stimulation in late and postpubertal females (Tanner IV-V), gen. pop.: general population; Het: assumed to be heterozygous for $\mathrm{CAH}$ according to HLA genotyping; - - -: upper range in general population.

Table 1. Hormonal responses in a father suspected to be affected with $C A H$, in known affected patients, and in a normal and heterozygous population

\begin{tabular}{lccccc}
\hline \multicolumn{1}{c}{ Population } & Number & \multicolumn{2}{c}{$\begin{array}{c}\text { 17-OHP level pre/post ACTH } \\
\text { Median }\end{array}$} & $\begin{array}{c}\text { Rate of increase of 17-OHP } \\
\text { Median }\end{array}$ (Range) & $\begin{array}{c}\text { Ratio 17-OHP/F } \\
\text { Median }\end{array}$ \\
(Range)
\end{tabular}

' Previously undiagnosed brother affected with CAH according to HLA genotyping and hormonal studies.

${ }^{2}$ Dexamethasone, $2 \mathrm{mg} / \mathrm{d}$ for 5 days.

\section{BASELINE VALUES OF 17-OHP}

Prepubertal and early pubertal heterozygote children showed a significantly higher baseline level of 17-OHP $(P<0.01)$ than the age and pubertal stage matched children from the general population (heterozygotes $1.47 \pm 0.9$, general population $0.6 \pm 0.4 \mathrm{ng}$ / $\mathrm{ml}$, mean $\pm 1 \mathrm{SD})$. However, there was some overlap between the heterozygous and the general population. The baseline 17-OHP level in late and postpubertal males (mean \pm SD: $1.7 \pm 1.0 \mathrm{ng} /$ $\mathrm{ml}$ ) and females (mean $\pm \mathrm{SD}: 1.3 \pm 0.9 \mathrm{ng} / \mathrm{ml}$ ) from the general population did not differ significantly from that of the heterozygotes (males: $2.0 \pm 0.9 \mathrm{ng} / \mathrm{ml}$; females $2.0 \pm 2.3 \mathrm{ng} / \mathrm{ml}$.

\section{STIMULATED 17-OHP VALUES}

The heterozygous prepubertal children showed a significantly higher ACTH stimulated level of 17-OHP, 17-OHP/F and rate of increase of 17-OHP compared to the prepubertal general population $(P<0.001)$ (Fig. 1). However, there were one or two overlapping values between the heterozygotes and general population for each parameter.

There was also a significant difference in the ACTH stimulated

\section{CAH GENOTYPES}

Pre-hormonal studies

Post-hormonal studies
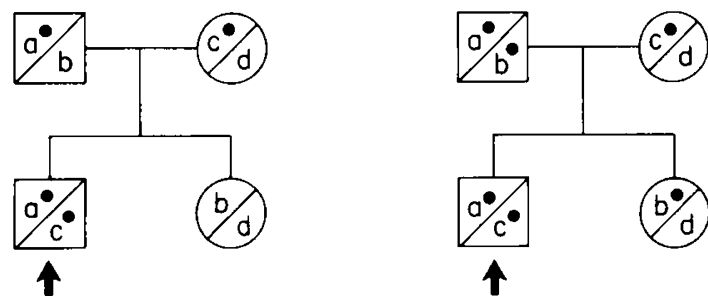

Fig. 4. Revision of interpretation of $\mathrm{CAH}$ genotyping before and after hormonal studies which revealed the father to be a patient with $\mathrm{CAH}$, $a, b, c$, and $d$ represent HLA haplotypes; $a^{\bullet}$ and $c^{\bullet}$ represent the HLA haplotypes lined with gene for $\mathrm{CAH}$ in the affected child $(\uparrow)$. Hormonal studies revealed the father to be affected and, thus, the $b$ haplotype was also linked with the gene for CAH. This resulted in reassignment of the sister as a heterozygote $\left(b^{\bullet} / d\right)$. 
level of 17-OHP, rate of increase of 17-OHP, and 17-OHP/F in the late pubertal and postpubertal heterozygote males compared to the general population $(P<0.001)$ (Fig. 2).

Neither the rate of increase nor the ratio of $17-0 \mathrm{OH} / \mathrm{F}$ showed overlapping values between heterozygous sibs and the unaffected sibs or general population in the late and postpubertal males.

Although there was a statistically significant difference in the ACTH stimulated 17-OHP levels, rate of increase of 17-OHP, and ratio of 17-OHP/F between the postmenarchal heterozygous females and the general population $(P<0.005,<0.01,<0.005$, respectively), there was considerable overlap in the values of the two groups (Fig. 3). All postmenarchal females were in the follicular phase of the menstrual cycle with the exception of one female in each group whose cycle was in the luteal phase.

The hormonal profile of a patient's father assumed to be heterozygous for CAH is shown in Table 1. The baseline 17-OHP level was 3-fold greater than the highest value of 17-OHP seen in the general and the heterozygous population. After ACTH stimulation, the rate of increase of 17-OHP and the ratio of 17-OHP/ $F$ were 5- to 7-fold greater than those of the general and heterozygous population, and 1.5- to 2.2-fold less than the response seen in the untreated patients with $\mathrm{CAH}$ after ACTH stimulation. The high baseline 17-OHP level $(10 \mathrm{ng} / \mathrm{ml})$ was suppressed to normal $(1.5 \mathrm{ng} / \mathrm{ml})$ after dexamethasone administration $(2 \mathrm{mg} /$ day for 5 days).

The HLA-genotypes and the assignment of 21-OH-def. genotypes for this family before and after hormonal studies are given in Figure 4. Both parents of the affected child with CAH were assumed to be heterozygous and the sister who did not share in HLA haplotype with the affected brother was considered to be homozygous normal before hormonal studies. This sister, however, had a hormonal response clearly consistent with the heterozygous state (Fig. 1). Further, the father demonstrated a hormonal response similar to other homozygous affected males. Therefore, the father was reassigned as a homozygous affected patient and the sister was reassigned to the heterozygous group (Figs. 1 and 4 ). Thus, the genotyping for $\mathrm{CAH}$ was revised based on the hormonal data.

One postpubertal male sib who was considered to be normal was found to be HLA identical with his three affected sisters. Hormonal studies confirmed that he was affected with $\mathrm{CAH}$ (Table 1)

\section{DISCUSSION}

This study demonstrates that both male sibs in all stages of puberty and premenarchal female sibs of patients with CAH (21$\mathrm{OH}$-def.) assigned to the heterozygous state by HLA genotyping are distinguishable hormonally from the general population.

In two unaffected sibs who should be homozygous normal for the 21-hydroxylase gene, based on HLA genotyping, the hormonal response was not different from the general population and was clearly distinguishable from the sibs assumed to be heterozygous carriers by HLA typing.

Thus, the measurement of 17-OHP and F after ACTH stimulation in general confirms the validity of HLA genotyping for assigning the 21-hydroxylase genotype to sibs of patients with this form of $\mathrm{CAH}$.

These hormonal studies in presumed heterozygotes for $\mathrm{CAH}$ based on HLA typing indicate the presence of a mild 21-hydroxylase enzyme deficiency as has been reported in obligate heterozygous parents $(2-4,7-10,12,13,17,18)$. In recent studies, GrosseWilde et al. (6) reported similar findings utilizing the measurements of 17-OHP 60 min after $\mathrm{ACTH}_{1-24}$ given iv in sibs predicted to be heterozygous by HLA genotyping and their parents.

Although there was a statistically significant difference in this study in hormonal values between postmenarchal heterozygous females and the general population, the hormonal test may fail to detect heterozygosity because of considerable overlapping data in these two groups. Knorr et al. (11) reported the administration of dexamethasone to the mothers before the test permitted a better separation between the heterozygote and control adult female response. If the hormonal response of a postpubertal female sib of a patient with $\mathrm{CAH}$ is in the overlapping range, HLA typing may be the only method of ascertaining heterozygosity.

The assignment of CAH genotype based on HLA genotyping assumes that the parent is heterozygous. Should a parent be an undetected patient with CAH, HLA genotyping will be misleading for the assignment of the CAH genotype. This is exemplified in the family illustrated in Figure 4.

HLA genotyping is valuable in screening family members of patients with CAH to observe the transmission of the gene. These studies revealed a previously undiagnosed sib with CAH who was HLA identical with three sibs affected with CAH. Hormonal studies confirmed the diagnosis of $21-\mathrm{OH}$-def. in this patient (Table 1). This is the second report in which HLA genotyping disclosed a previously undiagnosed patient (16).

In conclusion, hormonal studies in pre- and early pubertal male and female siblings and postpubertal male siblings have corroborated the assignment of CAH genotype based on HLA genotyping. However, in postmenarchal female sibs, hormonal studies did not clearly distinguish between the heterozygous and general population. Thus, HLA genotyping was a better method for the detection of heterozygosity for $\mathrm{CAH}, 21-\mathrm{OH}$ def., in the postpubertal females.

\section{REFERENCES AND NOTES}

1. Abraham, G. E., Buster, J. E., Lucas, L. A., Corrales, P. C., and Teller, R. C. Chromatographic separation of steroid hormones for use in radioimmunoassay. Analyt. Lett., 5: 509 (1972).

2. Bergada, C., Rivarola, M. A., and Cullen, M.: Respuesta a la metopirona en padres de enfermos con hiperplasia suprarrenal congenita. Excerpta Med. (Amst.) Int. Congr. Ser., No. 99, E 130 (1965).

3. Childs, B., Grumbach, M. M., and Van Wyk, J. J.: Virilizing adrenal hyperplasia; a genetic and hormonal study. J. Clin. Invest., 35: 213 (1956).

4. Cleveland, W. W., Nikezic, M., and Migeon, C. J.: Response to an $11 \beta$-hydroxylase inhibitor (SU-4885) in males with adrenal hyperplasia and in thei parents. J. Clin. Endocrinol. Metab., 22: 281 (1962)

5. Dupont, B., Oberfield, S. E., Smithwick, E. M., Lee, T. D., and Levine, L. S. Close genetic linkage between HLA and congenital adrenal hyperplasia (21hydroxylase deficiency). Lancet, 2: 1309 (1977).

6. Grosse-Wilde, H., Weil, J., Albert, E., Scholz, S., Bidlingmaier, F., and Knorr, D.: Linkage studies between HLA-A, B, D alleles and congenital adrenal hyperplasia (CAH). Pediatr. Res., 12: 1008 (1978).

7. Gutai, J. P., Kowarski, A. A., and Migeon, C. J.: The detection of the heterozygous carrier for congenital virilizing adrenal hyperplasia. J. Pediatr., 90: 924 (1977)

8. Hall, R., Smith, P. A., Harkness, R. A. and Smart, G. A.: A study of the parents of patients with congenital adrenal hyperplasia: detection of the heterozygote. Proc. Roy. Soc. Med., 63: 1040 (1970).

9. Homoki, J., Fazekas, A. T. A. and Teller, W. M.: Urirary excretion of pregnanetriolone in parents of children with 21-hydroxylase deficiency before and after stimulation with adrenocorticotropic hormone. In: P. A. Lee, L. P. Plotnick, A. A. Kowarski, C. J. Migeon: Congenital Adrenal Hyperplasia, p. 479 (University Park Press, Baltimore, 1977).

10. Knorr, D., Bidlingmaier, F., Butenandt, O., Schnakenburg, K. v., and Wagner, W.: Test for heterozygosity of congenital adrenal hyperplasia. In: P. A. Lee, L. P. Plotnick, A. A. Kowarski, C. J. Migeon: Congenital Adrenal Hyperplasia p. 495 (University Park Press, Baltimore, 1977).

11. Knorr, D., Bidlingmaier, F., Butenandt, O., Sippell, W. G. and Weil, J.: Progress in testing for heterozygosity in congenital adrenal hyperplasia (CAH). Pediatr. Res., 12: 1100 (1978).

12. Krensky, A. M., Bongiovanni, A. M., Marion, J., Parks, J., and Tenore, A. Identification of heterozygote carriers of congenital adrenal hyperplasia by radioimmunoassay of serum 17-OH progesterone. J. Pediatr., 90: 930 (1977).

13. Lee, P. A., and Gareis, F. J.: Evidence for partial 21-hydroxylase deficiency among heterozygote carriers of congenital adrenal hyperplasia. J. Clin. Endocrinol. Metab., 41: 415 (1975).

14. Levine, L. S., Zachmann, M., New, M. I., Prader, A., Pollack, M. S., O’Neill, G. J., Yang, S. Y., Oberfield, S. E., and Dupont, B.: Genetic mapping of the 21hydroxylase deficiency gene with the HLA linkage group. N. Engl. J. Med. 299: (in press) (1978).

15. Pang, S., Hotchkiss, J., Drash, A. L., Levine, L. S., and New, M. I.: Microfilter paper method for 17-hydroxyprogesterone radioimmunoassay: its application for rapid screening for congenital adrenal hyperplasia. J. Clin. Endocrinol. Metab., 45: 1003 (1977).

16. Price, D. A., Klouda, P. T., and Harris, R.: Letter to the Editor, Lancet, I: 930 (1978).

17. Qazi, Q. H., Hill. J. G., and Thompson, M. W.: Steroid studies in parents of patients with congenital adrenal hyperplasia. J. Clin. Endocrinol. Metab., 33 23 (1971).

18. Roux. H., Loras, B., and Forest, M. G.: Congenital adrenal hyperplasia caused by 21 -hydroxylase deficiency: plasma $17 \alpha$-hydroxyprogesterone in patients 
relatives. In: P. A. Lee. L. P. Plotnick. A. A. Kowarski, C. J. Migeon: Congenital Adrenal Hyperplasia, p. 487. (University Park Press, Baltimore, 1977).

19. Tanner, J. M.: In: Growth at Adolescence. 2nd Edition, p. 55. (Blackwell Scientific Publications, Oxford, 1962).

20. Weitkamp, L. R., Bryson. M., and Bacon. G. E.: Letter to the Editor. Lancet, I: 931 (1978).

21. The authors thank Dr. Ali Surve of Sandoz, Inc., NJ, and Professor Paul Vecsei. The University of Heidelberg, for providing antibodies for these studies and Mrs. Judy Pareira, Nurse Clinician, for assistance with the procedures.

22. Dr. Pang is the Clinical Associate Physician for the Pediatric Clinical Research Center, RR47 (Division of Research Resources, National Institutes of Health).

Copyright $\odot 1979$ International Pediatric Research Foundation, Inc. $0031-3998 / 79 / 1312-1360 \$ 02.00 / 0$
23. This research was supported, in part, by a grant (RR47) from the General Clinical Research Centers Program of the Division of Research Resources, NIH, and by NIH grant awards 1PO1 CA 22507, CA 08748, CA 19267. CA 17404, ROI EY 01616 and HD 00072 . This work was also supported by the Cornell University Medical College Samuel Z. Levine Fellowship Fund.

24. Requests for reprints should be addressed to: Lenore S. Levine. M. D., Department of Pediatrics, Division of Pediatric Endocrinology. The New York Hospital-Cornell Medical Center, 525 East 68th Street, New York, New York 10021 , USA.

25. Received for publication October 10, 1978.

26. Accepted for publication January 8, 1979. 